\title{
O PRELÚDIO DOS CURSOS TÉCNICOS DE ENFERMAGEM DA UNIVERSIDADE FEDERAL DO PIAUÍ
}

\section{THE PRELUDE TO TECHNICAL NURSING COURSES AT THE FEDERAL UNIVERSITY OF PIAUÍ}

\section{Natália Pereira Marineli ${ }^{1} *$ Layana Pachêco de Araújo Albuquerque ${ }^{2}$ * José de Ribamar $\operatorname{Ross}^{3} *$ Khelyane Mesquita de Carvalho ${ }^{4} *$ Lívia Maria Nunes de Almeida ${ }^{5}$ Mário Lopes Amorim6}

\section{RESUMO}

Objetivo: Discutir a trajetória histórica da criação dos cursos técnicos de enfermagem nas três escolas vinculadas à Universidade Federal do Piauí. Método: O estudo insere-se em uma abordagem sócio-histórica de caráter qualitativo. Utilizaram-se fontes primárias e secundárias, bem como a legislação que autoriza a criação do curso. A coleta de dados compreendeu as etapas: pesquisa em fontes documentais, entrevistas com colaboradores, sendo estes, docentes dos três colégios vinculados, totalizando oito colaboradores. Resultados: As falas revelam que os principais motivos que impulsionaram a origem dos cursos nas três escolas foram a demanda local, escassez de profissionais da área e interesses institucionais. Considerações finais: Pretende-se que este trabalho possa representar uma contribuição para a história e identidade da Enfermagem profissionalizante no Piauí, em especial, dos cursos Técnicos em Enfermagem.

Palavras-chave: Enfermagem; História da Enfermagem; Pesquisa Qualitativa; Técnicos de Enfermagem; Universidades.

\begin{abstract}
Objective: To discuss the historical trajectory of the creation of nursing technical courses in the three schools linked to the federal university of piauí. Method: The study is part of a qualitative socio-historical approach. Primary and secondary sources were used, as well as the legislation that authorizes the creation of the course. The data collection comprised the stages: research in documentary sources, interviews with collaborators, being these, teachers of the three linked colleges, totaling eight collaborators. Results: The speeches reveal that the main reasons that drove the origin of the courses in the three schools were local demand, shortage of professionals in the area and institutional interests. Final considerations: It is intended that this work may represent a contribution to the history and identity of professionalizing nursing in piauí, especially the technical nursing courses.
\end{abstract}

Keywords: Nursing; Nursing History; Nursing Technicians; Qualitative Research; Universities.

\footnotetext{
${ }^{1}$ Universidade Federal do Piauí, Colégio Técnico de Teresina. Teresina, Piauí, Brasil. ORCID: https://orcid.org/0000-0003-46963518

${ }^{2}$ Universidade Federal do Piauí, Departamento de Enfermagem. Floriano, Piauí, Brasil. ORCID: https://orcid.org/0000-0002-3714$787 \mathrm{X}$

${ }^{3}$ Universidade Estadual do Maranhão, Departamento de Enfermagem. Caxias, Maranhão, Brasil. ORCID: https://orcid.org/00000002-9362-8651

${ }^{4}$ Universidade Federal do Piauí, Colégio Técnico de Teresina. Teresina, Piauí, Brasil. ORCID: https://orcid.org/0000-0003-42703890

${ }^{5}$ Universidade Federal do Piauí, Departamento de Enfermagem. Floriano, Piauí, Brasil. ORCID: https://orcid.org/0000-0002-58574635

${ }^{6}$ Universidade Tecnológica Federal do Paraná, Programa de Pós-graduação em Tecnologia e Sociedade. Curitiba, Paraná, Brasil. ORCID: https://orcid.org/0001-9609-6154-4723
} 


\section{INTRODUÇÃO}

A história é a possibilidade de compreender fatos/acontecimentos por verossimilhança sobre o passado para a construção do conhecimento advindo da práxis profissional. A relação entre o passado e o presente é feita na busca por conhecimento, de modo a se indagar $\mathrm{o}$ passado em uma série de questões que são o "hoje". Esse "hoje" indubitavelmente influenciará o futuro. Além disso, as pesquisas históricas são imprescindíveis para a elaboração de boas práticas voltadas para as mais diversas áreas de atuação da enfermagem, como também tentar entender as lacunas do conhecimento quanto à trajetória da própria profissão ${ }^{(1-3)}$.

Em março de 1981, implementaram o primeiro curso técnico de enfermagem da Universidade Federal do Piauí (UFPI), no Colégio Técnico de Floriano (CTF), em regime de externato, que funcionava de modo integral e tinha duração de três anos ${ }^{(4-5)}$. E, apenas 25 anos depois, em 2006, o curso técnico em enfermagem do Colégio Técnico de Teresina (CTT) foi criado, em seguida, em 2010, o curso foi implantado no Colégio Técnico de Bom Jesus (CTBJ). Existem pouquíssimos estudos científicos que abordem a trajetória histórica da criação dos cursos técnicos em enfermagem da UFPI, mais precisamente uma tese e um artigo, retratando as dificuldades, conquistas e fatos que impulsionaram ou retardaram esse https://doi.org/10.31011/reaid-2021-v.95-n.36-art.1232 Rev Enferm Atual In Derme v. 95, n. 36, 2021 e-021145 processo.

Ressalta-se que, para analisar, questionar e interpretar o percurso histórico é necessário que se reflita sobre a produção de conhecimento relacionado à história e memória, nas suas mais diversas dimensões. A procura pela preservação da memória e história do ensino da enfermagem no estado do Piauí é de fundamental importância para os questionamentos, análises e descobertas sobre o desdobramento e desenvolvimento deste ensino $^{(6)}$. Pesquisas realizadas em instituições ligadas à enfermagem afirmam que, conhecer a história, contribui para a consolidação da sua identidade, sendo indispensável o aprofundamento teórico no estudo histórico para auxiliar a análise da profissão de enfermagem $^{(7-9)}$.

Portanto, o objetivo deste estudo é discutir a trajetória histórica da criação dos cursos técnicos de enfermagem nas três escolas vinculadas à UFPI.

\section{MÉTODOS}

O presente estudo insere-se em uma abordagem sócio-histórica de caráter qualitativo. Esse tipo de pesquisa qualitativa compreende os estudos dos grupos humanos no seu espaço temporal e se preocupa em discutir os variados aspectos do cotidiano das diferentes classes e grupos sociais ${ }^{(11)}$. Também foi realizada a análise documental como técnica inicial de coleta de dados. Para a execução do estudo proposto foram 
utilizados recursos fornecidos pela História oral temática.

Para a análise dos dados qualitativos, além da História oral temática, fundamentouse ainda no método de história oral híbrida que se destaca por ir além do uso exclusivo das entrevistas, além das gravações, e por promover a mescla de análises derivadas das entrevistas cruzadas com outros documentos. Assim, unem-se às entrevistas outros documentos como os cartoriais, reportagens, escritos, dados estatísticos, literatura, entre outros $^{(11)}$.

O estudo foi realizado nos três Colégios Técnicos vinculados à Universidade Federal do Piauí. Os Colégios Técnicos situam-se em Teresina (Colégio Técnico de Teresina- CTT), em Floriano (Colégio Técnico de Floriano- CTF) e em Bom Jesus (Colégio Técnico de Bom Jesus- CTBJ). O recorte histórico tem como marco inicial a criação do primeiro curso técnico de enfermagem da UFPI, que ocorreu no Colégio Técnico de Floriano, em 1981, seguindo até a criação do curso técnico em enfermagem em Bom Jesus, no ano de 2010.

As imagens dos três colégios técnicos encontram-se representadas nas figuras 1 a 3 .

Figura 1 - Colégio Técnico de Teresina (CTT). Teresina, PI, Brasil, 2019.

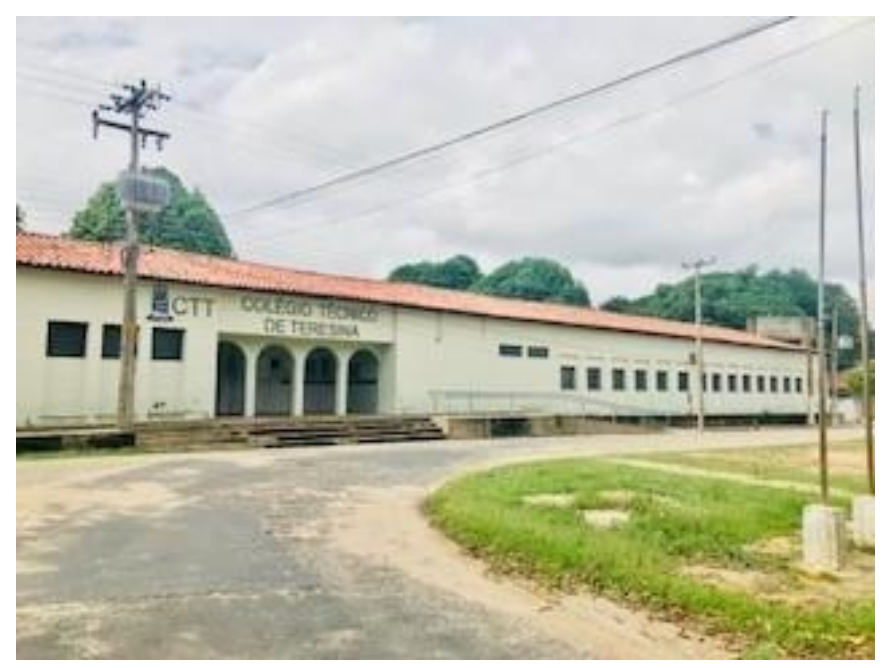

Fonte: Elaborado pelos autores 
Figura 2 - Colégio Técnico de Floriano (CTF). Teresina, PI, Brasil, 2019.

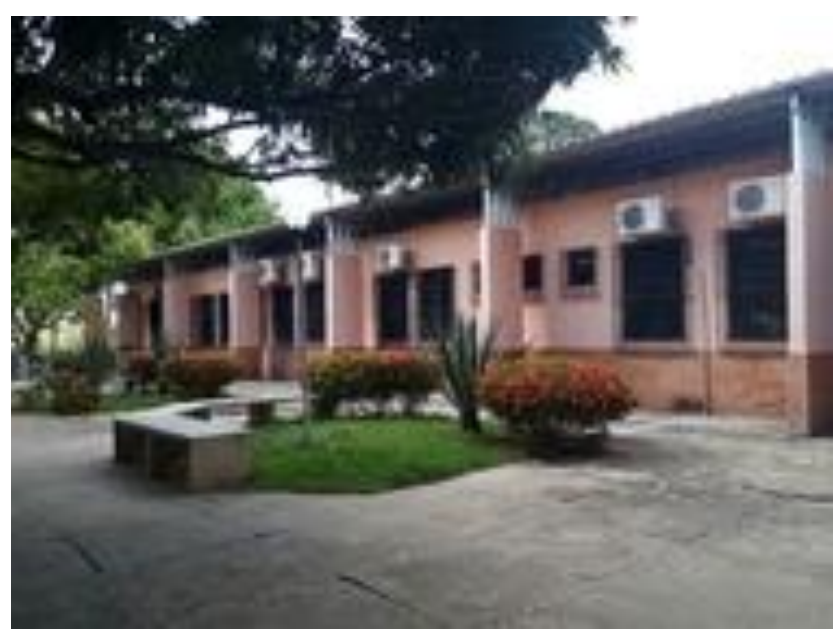

Fonte: Elaborado pelos autores

Figura 3 - Colégio Técnico de Bom Jesus (CTBJ). Teresina, PI, Brasil, 2019.

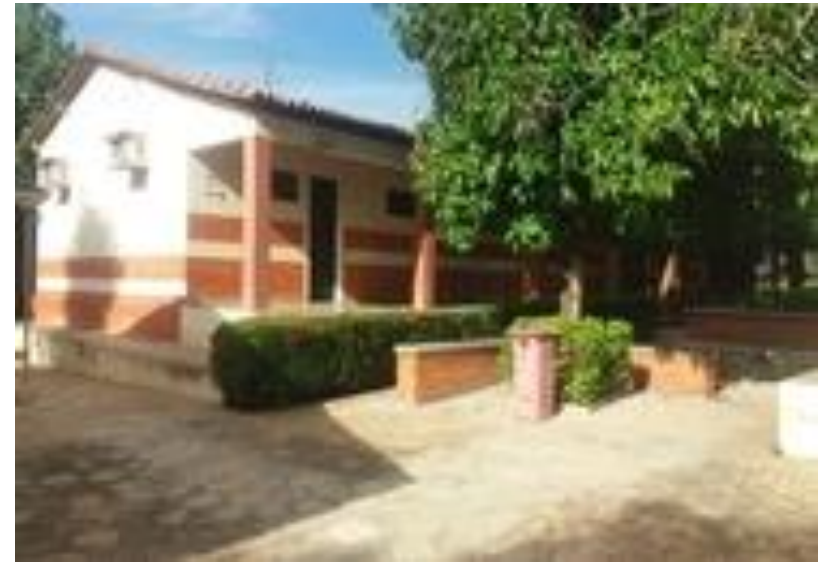

Fonte: Elaborado pelos autores

A coleta de dados compreendeu as seguintes etapas: pesquisa em fontes documentais e, em seguida, entrevistas com colaboradores. Inicialmente, foram realizadas as buscas de fontes documentais escritas que disponibilizaram informações pertinentes ao estudo existentes na Universidade Federal do Piauí e nos três colégios técnicos. A análise documental foi realizada estabelecendo-se ordem cronológica nas fontes documentais.
Utilizaram-se fontes primárias (documentos oficiais da instituição, história oral dos precursores do curso) e secundárias (artigos e livros produzidos sobre os Colégios Técnicos, bem como a legislação que autoriza a criação do curso de enfermagem em nível técnico). Os colaborados foram intencionalmente selecionados, por terem feito parte do processo de criação nos referidos cursos supracitados, totalizando oito professores. 
As entrevistas foram realizadas utilizando-se um roteiro semiestruturado, permitindo que os colaboradores relatassem de forma livre as suas memórias, cujo foco seria a trajetória histórica da criação dos cursos técnicos em enfermagem da Universidade Federal do Piauí, obedecendo-se a dois procedimentos: a gravação e a transcrição. Os depoimentos foram gravados em aparelho celular iPhone modelo XS. As entrevistas ocorreram nos meses de maio de 2018 a agosto de 2019, como duração em média de 45 min. Foram realizadas pessoalmente, na cidade de Floriano e Teresina, exceto uma que foi realizada via telefone, em acordo com o colaborador.

Após a entrevista houve a transcrição e a transcrição dos áudios. A análise dos dados qualitativos foi realizada após o mapeamento das entrevistas e das fontes documentais. A princípio, foram extraídas as evidências e falas de acordo com o tema proposto, agrupando-as em dois lados e comparando-as em uma sequência cronológica de acontecimentos, para a análise temática sobre a criação do curso técnico em enfermagem da UFPI. A interface entre o produto das entrevistas e os registros documentais promove o entendimento de como esse contexto histórico foi determinante para a consolidação do curso técnico em enfermagem da UFPI.

Respeitando os preceitos éticos estabelecidos pela Resolução 466/12 do
Conselho Nacional de Saúde (CNS) do Ministério da Saúde, que dispões sobre pesquisa com seres humanos ${ }^{(12)}$, o projeto foi submetido à apreciação do Comitê de Ética e Pesquisa da Universidade Federal do PiauíUFPI, sendo aprovado com o parecer 2.445.793. Em relação aos colaboradores, após serem esclarecidos sobre os objetivos da pesquisa e os procedimentos utilizados, os mesmos assinaram o Termo de Consentimento Livre Esclarecido (TCLE). Os trechos dos depoimentos estão identificados no texto pelos sobrenomes dos colaboradores, pois as entrevistas foram validadas pelos mesmos para a publicação, através da assinatura do Termo de Cessão de Entrevista (TCE).

\section{RESULTADOS}

Fizeram parte do estudo os primeiros coordenadores dos cursos técnicos de enfermagem, membros das comissões designadas para a criação dos cursos e elaboração do Projeto para sua criação, os primeiros docentes, os diretores das escolas da ocasião e alguns docentes dos cursos da época de criação. Todos eles docentes dos três colégios vinculados, na ativa ou já aposentados, totalizando oito colaboradores.

\section{O início do Curso Técnico de Enfermagem no CTF}


Floriano é uma cidade considerada como o principal centro educacional do sul do estado do Piauí, sendo referência para municípios piauienses e maranhenses. Situase à margem direita do rio Parnaíba e localizase a $253 \mathrm{~km}$ da capital Teresina. Possui 57.690 habitantes, de acordo com o último censo realizado pelo IBGE, tendo o setor saúde um papel prevalecente no mercado de trabalho do município, bem como nos municípios pertencentes à sua microrregião ${ }^{(13-}$ 14).

Quando implantado no Colégio Agrícola de Floriano, hoje CTF, o Curso Técnico de Enfermagem visou atender uma carência de profissionais de enfermagem legalmente habilitados de vários municípios $^{(14)}$. Como não existia curso técnico de enfermagem na cidade de Floriano na época, havia uma necessidade de profissionais capacitados na área da enfermagem, para atender principalmente a demanda dos pacientes do Hospital Estadual Tibério Nunes.

O hospital que eu trabalhava estava sendo multado. Eu tinha que selecionar uma pessoa, alguém que dissesse: "eu quero trabalhar com enfermagem!". Então eu a treinava e via se tinha condições para trabalhar. Porque na época não tinha ninguém com formação adequada (SANTOS, depoimento oral, 2019).

Tinha o hospital de Tibério Nunes, que havia sido inaugurado. Acredito que o curso técnico de enfermagem foi para Floriano pela própria necessidade, tinha um hospital do estado, uma demanda boa de pacientes. (REIS, depoimento oral, 2019).

Os relatos levam a crer que, impulsionados pela necessidade da população e instituições de saúde local, aliada à vontade política, fomentaram a criação do curso técnico de enfermagem na cidade de Floriano. Além disso, um hospital da cidade corria o risco de ser multado pelo Ministério do Trabalho na época, pois lá existiam poucos profissionais de enfermagem oficialmente habilitados para atender essa demanda de pacientes que necessitavam de assistência à saúde:

Certa vez um representante do Ministério do Trabalho veio até o hospital e quis multar, pois nós não tínhamos ninguém devidamente preparado. Nós tínhamos poucas auxiliares de enfermagem lá em Floriano (SANTOS, depoimento oral, 2019).

Sobre esse assunto, ressalta-se que a profissionalização dos trabalhadores de enfermagem tem como um de seus objetivos a capacitação destes profissionais e o fortalecimento das escolas técnicas de saúde, buscando melhoria da qualidade do atendimento à população, além de propiciar o aumento de oportunidade para os grupos de trabalhadores de nível médio, para que possam exercer a profissão com consciência e responsabilidade, nos mais diferentes níveis de atuação, sejam eles promoção, recuperação ou reabilitação da saúde ${ }^{(15)}$. Estudar a história de uma instituição estabelece um esforço 
importante para o conhecimento da História da Enfermagem no Brasil.

Em junho de 1980, o então reitor da UFPI, Camilo da Silveira convocou uma reunião com algumas enfermeiras da cidade de Floriano no CTF, para tratar dos assuntos relacionados à criação do curso técnico de enfermagem. Na ocasião, a enfermeira Lígia Beatriz da Costa e Silva Ribeiro Santos trabalhava na diretoria da regional de saúde de Floriano, que incluía a supervisão de mais de 20 municípios:

Como eu trabalhava na diretoria regional de saúde, e conhecia todos os municípios, o reitor da Universidade, professor Camilo da Silveira, chegou em Floriano e convocou as enfermeiras da cidade, dizendo que ele pretendia fundar o curso técnico lá. Eu, como sempre, gosto de chegar bem cedo aos locais de reunião, e cheguei meia hora antes... e nós começamos a conversar (SANTOS, depoimento oral, 2019).

O doutor Amílcar tinha a intenção de levar o curso para Floriano, para ele, parece que era uma satisfação pessoal e de crescimento para a cidade... ele demonstrava muito esse interesse para nós nas primeiras reuniões que tivemos... começamos a ter nossas primeiras conversas em junho se não me engano (CARVALHO, depoimento oral, 2019).

A partir de uma conversa informal entre o reitor e a enfermeira Lígia, iniciada antes da reunião propriamente dita, surgiu o convite para a coordenação do curso técnico em enfermagem, que seria implantado posteriormente. Em seguida, o professor Camilo solicitou que a mesma começasse a elaborar o projeto do curso e tomar as medidas legais para assumir o cargo proposto:

Quando todo mundo chegou para a reunião, eu já era coordenadora do curso. Como ele viu que eu entendia do processo todo da regional ele disse: "Você topa ser coordenadora do curso de enfermagem?" Eu disse: "Topo". E mandou que eu começasse a fazer o projeto, que eu pedisse demissão da secretaria de saúde, onde eu trabalhava como coordenadora, pra eu ir trabalhar lá. $\mathrm{E}$ eu assim o fiz. (SANTOS, depoimento oral, 2019).

A reunião já foi para tratar do início do curso, já tinha por exemplo a Lígia, tinha contato maior, e depois fomos convidadas, eu, Anatália e Isabel (CARVALHO, depoimento oral, 2019).

Entre os anos de 1960 a 1980, a Escola de Enfermagem Irmã Maria Antoinette Blanchot foi a instituição de ensino de enfermagem mais importante no estado do Piauí. A referida escola foi desativada no início da década de 1980, de acordo com relatos de pessoas que vivenciaram a conjuntura na época, em consequência da ausência de doações, de verbas, e da ajuda do governo Estadual para as despesas de manutenção da escola e para o pagamento dos salários dos professores ${ }^{(16-17)}$; $\mathrm{Na}$ ocasião, a futura coordenadora, professora Lígia, viajou para Teresina para conhecer as dependências da escola Antoinette Blanchot, prestes a fechar suas portas, fato ainda desconhecido pela professora naquele momento. $\mathrm{O}$ objetivo da visita era observar o funcionamento do 
curso para idealizar o projeto para a implantação do curso técnico em enfermagem em Floriano:

Para implantar o curso ainda tive que viajar para conhecer a escola Antoinette Blanchot, que tinha o curso técnico de enfermagem. Para eu ir conhecer, ver como funcionava, com o objetivo de ter uma base implantar, fazer o projeto e idealizar o curso em Floriano (SANTOS, depoimento oral, 2019).

As primeiras professoras do curso foram as enfermeiras Ligia Beatriz Lígia Beatriz da Costa e Silva Ribeiro Santos, Isabel Pereira Neves, Iracema de Almeida Carvalho, Anatália de Almeida Reis e Maria Neuma Dias Castor de Melo. O recrutamento das primeiras professoras se deu através de convite, sendo feita a seleção por afinidade com as disciplinas inicialmente ofertadas. A professora Lígia, que ficou responsável por elaborar a matriz curricular do curso na época, o fez baseado nas premissas exigidas pelo MEC; para tanto, além da Escola de Auxiliares e Técnicos de Enfermagem Maria Antoinette Blanchot, visitou também outras escolas como em São Luís (MA) e em Pernambuco. Inicialmente o curso foi proposto como pós-médio, e em seguida, concomitante.

A professora Ligia enviou um convite às enfermeiras da cidade para participar da seleção, levando os seus respectivos currículos. Fomos eu, Neuma, Iracema, Isabel e outras. Então nós começamos, e a partir daí as outras que entraram já foram através de concurso. Como eram poucas enfermeiras na cidade, não houve um concurso, houve uma seleção de currículos (REIS, depoimento oral, 2019).

O curso foi sendo implantado com muita dificuldade porque não existia concurso para professor na época (SINIMBÚ NETO, depoimento oral, 2019).

\section{O início do Curso Técnico de Enfermagem no CTT}

Em 1998, dezessete anos após a criação do curso técnico de enfermagem em Floriano, houve a elaboração de um projeto com aprovação do MEC para a criação de outro curso técnico de enfermagem em outra escola técnica vinculada à UFPI, só que dessa vez na capital, Teresina, por iniciativa da professora Rita Magalhães Mendonça. A comunidade solicitava o curso técnico de enfermagem no CTT, havia bastante procura; existia um espaço físico suficiente, suporte e estrutura, como sala de aulas, laboratório e campo de estágio. Além disso, havia uma demanda na cidade de Teresina, após uma pesquisa feita nos hospitais da cidade, demanda esta que solicitava uma qualificação de integrantes da equipe de enfermagem, tendo em vista que o MEC orientava os auxiliares de enfermagem a complementarem a sua formação para técnicos de enfermagem, como demonstram as falas a seguir:

$\mathrm{Na}$ época um curso técnico de enfermagem era muito procurado, as pessoas precisavam, e o CTT estava lá à disposição com muitas salas e espaço, a gente tinha o suporte e toda 
a estrutura. E por que não? (MENDONÇA, depoimento oral, 2019).

Fizemos uma pesquisa e, em Teresina, nós descobrimos que tinha 615 auxiliares de enfermagem nos hospitais que eram conveniados com o município. E aí a gente resolveu abrir, para uma melhor qualificação para eles como técnicos (SINIMBÚ NETO, depoimento oral, 2019).

Naquela época, em 1998, a direção da escola criou uma comissão no CTT, com a professora Rita Magalhães Mendonça, o professor Francisco de Assis Sinimbú Neto, professor do curso técnico de agropecuária, e o professor José da Fonseca Castelo Branco, que também era professor do curso técnico de agropecuária, tendo como presidente a primeira, com o intuito elaborar a projeto para a criação do curso técnico de enfermagem em Teresina.

$\mathrm{Na}$ oportunidade, a comissão buscou auxílio em outras escolas técnicas do país, mais especificamente a escola técnica da cidade de Natal, denominada atualmente de Escola de Enfermagem de Natal (EEN), com a finalidade de buscar orientações sobre a matriz curricular, funcionamento do curso propriamente dito, organização e material necessário. Apesar de tentativas de parceria com as professoras da graduação do curso de enfermagem da própria UFPI na época, as mesmas não demonstraram interesse em contribuir, e tão pouco em prestar auxílio para que o curso de fato acontecesse, expressados nas seguintes falas:
$\mathrm{Na}$ época nós fizemos uma viagem pra Natal - RN, para visitar a escola técnica de enfermagem de lá. E nós a ficamos observando e recebendo orientações de várias escolas técnicas sobre como poderia funcionar o curso, a matriz curricular, para que pudéssemos organizar tudo (MENDONÇA, depoimento oral, 2019).

Inicialmente houve uma negativa de pessoas que nós convidamos do curso superior, não encabeçaram a proposta do curso técnico. Não tiveram o menor interesse (SINIMBÚ NETO, depoimento oral, 2019).

A divisão social do trabalho da enfermagem é historicamente definida por Florence Nigthingale, com a implementação das categorias "nurse" e "lady - nurse". As "ladies-nurses" eram provenientes da burguesia, e eram responsáveis por atividades administrativas de supervisão do cuidado e do ensino, ou seja, o trabalho intelectual. Já as "nurses", que eram oriundas do proletariado, ficavam responsáveis o cuidado propriamente dito, ao doente. Tal divisão social do trabalho, na enfermagem brasileira, foi ampliada e aprimorada com uma maior segmentação dos cuidados, prestados por suas categorias. Dentre estas categorias, estão as enfermeiras, que desfrutam de maior prestígio, melhor remuneração e que tem menos contato com o cuidado ao paciente ${ }^{(18)}$.

A proposta então foi levada para o Ministério da Educação, em Brasília e logrouse êxito. Apesar da aprovação publicada no diário oficial em 10 de junho de 1998, na seção $1, n^{\circ} 109$, página 22, porém, apenas oito anos depois o curso de fato foi iniciado no 
CTT. Os discursos revelam que divergências políticas entre a diretoria da escola e a Reitoria, culminaram no arquivamento do processo, e impedimento de sua continuação até o ano de 2006. Porém, a falta de apoio por parte da reitoria ocorria de forma sutil e era captada nas entrelinhas das conversas, de acordo com as falas declaradas:

O curso foi aprovado, inclusive no Diário Oficial da União (DOU), só que o reitor da época não autorizou a liberação do nosso curso para funcionar, o projeto ficou engavetado durante muitos anos, durante todo mandato dele na universidade, acho que uns 6 anos ou 8 anos, não recordo exatamente (MENDONÇA, depoimento oral, 2019).

Nós levamos o projeto do curso ao MEC em Brasília e houve um sinal verde. Conversamos com o reitor da época e tivemos a aprovação no Diário Oficial da União. Foi aprovado e tudo, publicado no DOU, mas ficou em stand-by (SINIMBÚ NETO, depoimento oral, 2019).

Um acordo realizado em 2004 com o candidato à reitoria, professor Luís de Sousa Santos Júnior, viabilizou a continuidade do processo e implementação do curso. Em reunião com o candidato referido, o mesmo assumiu o compromisso de dar seguimento com o projeto de criação do curso na escola, em troca do apoio à sua candidatura à reitoria. Sendo assim, o professor Júnior, como é conhecido, venceu às eleições à reitoria, e em 2006 tinha início a primeira turma do curso técnico em enfermagem do CTT.

Durante uma reunião de campanha do professor Luís dos Santos Junior, nós fizemos esse pedido: que ele desengavetasse nosso projeto $\mathrm{e}$ colocasse nosso curso para funcionar porque existia uma necessidade muito grande. E foi uma promessa dele, e, quando ele assumiu a reitoria, realmente colocou o curso para funcionar e o curso começou a partir de 2006 (MENDONÇA, depoimento oral, 2019).

Nós chamamos um candidato a reitoria durante a campanha eleitoral aqui na escola, e ele nos pediu apoio. $\mathrm{E}$ nós dissemos para ele que daríamos todo o apoio, desde que ele também desse apoio para a abertura do curso que já estava aprovado pelo MEC. E assim o candidato a reitor disse: na hora que eu assumir, eu encabeço isso com vocês. E assim fez (SINIMBÚ NETO, depoimento oral, 2019).

Tão logo o reitor Luís Júnior assumiu, foram dados os prosseguimentos para a contratação de professores. Diferentemente de Floriano, os primeiros professores realizaram o processo seletivo através de concurso público, exceto a professora Rita que já havia sido efetivada em Bom Jesus, como explicitado acima.

Somente no ano de 2006 é que o curso técnico de enfermagem foi criado em Teresina, ambos vinculados à UFPI. O processo seletivo para o preenchimento dos códigos de vaga aconteceu na própria cidade, no ano de 2005, por meio do edital $n^{\circ} 2 / 2005$, no qual havia duas vagas. $\mathrm{O}$ aviso de edital foi publicado nos principais meios de comunicação veiculados na cidade naquela época, como o jornal Diário do Povo e o Jornal O Dia, ambos na capital do Piauí.

Foi então que abrimos o primeiro concurso para a Enfermagem daqui. 
A gente sabia que para o curso funcionar bem, deveria ter de seis a sete professores, mas começamos com quatro. (SINIMBÚ NETO, depoimento oral, 2019).

Concomitantemente da aprovação do projeto, a gente já foi também se preocupando em começar a comprar materiais para montar o nosso laboratório. Nós fomos comprando aos poucos, tanto que, quando o curso abriu, mesmo com os professores já contratados, a gente já tinha alguns equipamentos para nosso laboratório funcionar (MENDONÇA, depoimento oral, 2019).

As primeiras colocadas no concurso foram as professoras Rosana dos Santos Costa ( $1^{\circ}$ lugar), Rosilane de Lima Brito Magalhães (2 $2^{\circ}$ lugar), Adélia Dalva da Silva Oliveira ( $3^{\circ}$ lugar), Sheila Coelho Ramalho Vasconcelos (4ํㅣㄹ lugar), Malvina Thaís Pacheco Rodrigues ( $5^{\circ}$ lugar), Conceição de Maria Franco Sá Nascimento ( $6^{\circ}$ lugar), Juscélia Maria de Moura Feitosa Veras ( $7^{\circ}$ lugar), Lucíola Galvão Gondim Corrêa Feitosa ( $8^{\circ}$ lugar), Noélia Mota de Sousa ( $9^{\circ}$ lugar), e Ana Gabriela Barroso Leal (10 $10^{\circ}$ lugar), de acordo com o Ato da Reitoria $n^{\circ} 1298 / 05$, de 09 de setembro de 2005. A primeira coordenadora do curso técnico de enfermagem do CTT foi a professora Rita de Cássia, nomeada em 02 de janeiro de 2006, de acordo com a portaria $n^{\circ}$ 002/2006, sob a gestão do diretor professor Sinimbú.

\section{O início do Curso Técnico de Enfermagem no CTBJ}

Quatro anos depois da criação do curso técnico de enfermagem do CTT em Teresina, no ano de 2010, iniciavam-se as aulas do curso técnico de enfermagem de Bom Jesus, localizado ao sul do Piauí, no CTBJ. No ano de 2006, teve início um projeto de expansão do CTBJ, financiado pelo PROEP (Programa de Expansão da Educação Profissional) onde constava a melhoria e expansão da estrutura física do CTBJ, bem como a oferta de novos cursos técnicos ${ }^{(19)}$. Em 2008, o diretor do CTBJ, o professor Raimundo Falcão Neto (conhecido como Tetuca), motivado pela demanda local e permissão da administração superior da UFPI, convidou uma comissão de professores para a elaboração de um projeto para levar um novo curso técnico para a instituição referida.

Aí foi feita uma equipe de
professores para trabalhar em cima
desse projeto que nós iríamos
elaborar para o CTBJ (CRUZ,
depoimento oral, 2019).
Na época, o professor Tetuca me
chamou para fazer parte de uma
comissão para a elaboração do
projeto e levar o curso técnico de
enfermagem para Bom Jesus. O
reitor já tinha aprovado e eu tinha
experiência em elaboração de
projetos. Então começamos (SILVA,
depoimento oral, 2019).

De acordo com os relatos, a comissão e o sobredito diretor decidiram implantar o curso técnico de enfermagem em Bom Jesus por diversos motivos, dentre eles: era um curso que atenderia a necessidade local tendo em vista que nem em Bom Jesus, nem nos municípios próximos existiam esse curso; era 
uma demanda das instituições de saúde da região, pois existiam muitos auxiliares de enfermagem que pretendiam complementar a formação; alguns membros da comissão sobredita vinham de uma série de experiências anteriores como docente em cursos técnicos de enfermagem de outras instituições no estado do Piauí; e , além disso, já exista o curso nas duas escolas técnicas vinculadas à UFPI, faltando apenas o CTBJ ofertar o curso.

Era uma demanda da região, e conversando com a comunidade eles sentiram a necessidade de um curso na área da saúde. Entrando em contato com o reitor, ele disse que fizéssemos o projeto e que ele daria sequência e contrataria os professores que fossem necessários, melhoraria a infraestrutura da escola para que fosse implantado esse curso, e assim fizemos (FALCÃO NETO, depoimento oral, 2019).

A gente tinha lá só o curso técnico em agropecuária, por isso o nome Colégio Agrícola de Bom Jesus. Aí foi surgindo a necessidade de outros cursos, e um dos cursos mais procurados pela população de Bom Jesus era um curso de enfermagem. As pessoas sempre perguntavam. Então surgiu a ideia de a gente montar esse curso (CRUZ, depoimento oral, 2019).

Para afirmar esse déficit de cursos da saúde em escolas técnicas públicas no país ${ }^{22}$ foi realizada uma pesquisa com todos os profissionais que tinham registro no COREN no Brasil, chamando atenção para o fato dos resultados da pesquisa intitulada "Perfil da Enfermagem no Brasil": maior participação do setor privado na formação técnica em saúde; e cresceu, ainda mais, ao longo da década posterior, em 2009. Apenas $24,7 \%$ dos matriculados em cursos técnicos na área da saúde estavam vinculados a escolas técnicas públicas. Os autores afirmam a necessidade de ações de intervenções para mudanças deste cenário $^{(20)}$. A criação de cursos da área da saúde nas escolas vinculadas às universidades brasileiras seria uma alternativa para isso.

Em anuência com a escolha do curso, a comissão formada por três professoras do CTBJ: Maria Majací Moura da Silva Oldênia e Maria Angélica Piauilino da Cruz, ambas professoras do Ensino Médio do CTBJ, iniciaram a elaboração do projeto. Em seguida, a professora Majací, por morar em Teresina e ter acesso facilitado às escolas técnicas da cidade, obteve alguns projetos de cursos técnicos de enfermagem de algumas instituições, inclusive do CTT e CTF. A partir destes projetos, a comissão elaborou um projeto de acordo com a realidade da escola, para que atendesse a demanda de Bom Jesus e dos municípios circunvizinhos.

A professora Majací muito empolgada com essa questão, como sempre foi, se disponibilizou e foi a primeira a querer participar. Foi formada a comissão que elaborou esse projeto, pegando inclusive o projeto aqui do CTT, além de projetos de outras escolas para analisar e avaliar, e daí elaborar o nosso (FALCÃO NETO, depoimento oral, 2019).

Naquele contexto, não existiam ainda professores efetivos na área da 
enfermagem no CTBJ, sendo nomeada então, a professora Maria Angélica como a primeira coordenadora do curso técnico de enfermagem do CTBJ. A primeira seleção de professores veio através de concurso, apenas no ano de 2010 tendo como aprovados os professore Maria Augusta e Cristiane Teixeira, iniciando as aulas da primeira turma do curso técnico de enfermagem do CTBJ.

A primeira coordenadora do curso técnico de enfermagem de Bom Jesus foi Maria Angélica, porque não tinha nenhum professor efetivo da área naquela época (FALCÃO NETO, depoimento oral, 2019).

Não tinha nenhum professor da área da enfermagem, como ainda não existia um curso, não tinha professor da área. Então eram uns professores definitivos da escola, só que de outras áreas. No primeiro momento me chamaram para ser coordenadora, e eu aceitei coordenar (CRUZ, depoimento oral, 2019).

Um estudo realizado sobre a história do curso profissionalizante de enfermagem do Centro Estadual de Educação profissional Pedro Barretto Neto - CEEP situado na cidade de Cascavel-PR, mostrou que a iniciativa do referido curso também foi determinada pelos movimentos políticos e econômicos do contexto em que se encontrava, tendo como justificativa a formação profissional capacitada, garantindo a assistência de enfermagem para suprir a necessidade existente na área da saúde ${ }^{(21)}$.

A implementação do primeiro curso técnico de enfermagem no Rio de Janeiro, que aconteceu na Escola de Enfermagem Anna Nery da Universidade Federal do Rio de Janeiro, em 11 de abril de 1966, foi realizada por enfermeiras possuidoras de representatividade política. É necessário conhecer os meandros dos interesses sociais, políticos e econômicos que possam estar envolvidos na criação e na trajetória dos cursos técnicos de enfermagem, bem como na figura dos profissionais, para a compreensão das questões relacionadas aos motivos de seu início $^{(22)}$.

Os depoimentos dos colaboradores deste estudo, em relação aos fatores que impulsionaram a criação dos cursos técnicos de enfermagem da UFPI nos três colégios convergem em um mesmo ponto: a existência da demanda local, relacionada à assistência de enfermagem habilitada formalmente. As falas dos entrevistados também apontam que entre acordos políticos, iniciativas individuais e necessidades da própria região fomentaram iniciativas para a criação dos cursos acima referidos.

\section{CONSIDERAÇÕES FINAIS}

A pesquisa discutiu a trajetória histórica de criação dos cursos técnicos de enfermagem das escolas vinculadas à UFPI. As falas revelam que os principais motivos que impulsionaram a origem dos cursos nas três escolas foram a demanda local, a procura por parte da população e os interesses 
políticos institucionais. $\mathrm{O}$ primeiro curso foi inaugurado em Floriano, desde o início idealizado para esta cidade. Teresina passou por um processo de criação mais demorado, pois entre a autorização do MEC e o início das aulas propriamente dito, passaram-se 8 anos. Por fim, o curso foi ofertado em Bom Jesus. As três escolas, de acordo com os discursos, possuíam estrutura física e recursos adequados para a manutenção do curso.

Os resultados desta pesquisa trouxeram informações relevantes para $\mathrm{o}$ conhecimento da origem dos cursos técnicos de enfermagem da referida Universidade, mas, além disso, demonstram uma realidade que reverbera em todo país. A categoria de enfermagem é imprescindível dentro da equipe multidisciplinar, sendo de extrema necessidade que conheçamos as suas origens, para que os profissionais e futuros profissionais se reconheçam dentro do labor, bem como valorizem a sua trajetória histórica. Dessa maneira, como conhecedores da importância do resgate histórico para a consolidação do curso e da profissão, é que se reforça a importância desse estudo para a preservação da memória dos profissionais da enfermagem, tornando-se também um componente importante da história dos discentes e docentes deste curso.

Apesar da pesquisa ser pioneira em sua concepção, a mesma apresentou limitações em relação aos aspectos operacionais e logísticos frente à distância de deslocamento para as cidades de realização das entrevistas. Outra grande limitação foi que as escolas fundadas nas décadas de 80 apresentou grande parte do seu corpo docente aposentado, havendo grande dificuldade para localizar esses colaboradores.

O estudo em questão apresenta uma importante fonte de pesquisa relacionada à história dos cursos técnicos de enfermagem da UFPI, tendo em vista que não existe na literatura cientifica pesquisas mais aprofundadas sobre a temática. Pretende-se que este trabalho possa representar uma contribuição para a história e identidade da Enfermagem profissionalizante no Piauí, em especial, dos cursos Técnicos em Enfermagem da UFPI.

\section{REFERÊNCIAS}

1. Padilha MICS, Borenstein MS. Nursing History: Teaching, research and interdisciplinarity. Esc Anna Nery Rev Enferm [Internet]. 2006 [citado 2020 Mar 2];10(3):532-8.

DOI: https://doi.org/10.1590/S141481452006000300024

2. Vieira NA, Petry S, Padilha MI. Best Practices in Historical Studies of Nursing and Health (1999-2017). Rev Bras Enferm [Internet]. 2019 [citado 2020 Mar 2];72(4):1027-33. DOI: https://doi.org/10.1590/0034-7167-2018-0538

3. Bittencourt RC, Santos TCF, Abreu MAS, Filho AJA, Peres MAAP, Aperibense PGGSA. Historical evolution of: configuration of the nursing team in a military hospital. Rev Rene (Online) [Internet]. 2019 [citado 2020 Mar 2];20:e41557. DOI: 
https://doi.org/10.15253/2175-

6783.20192041557

4. Universidade Federal do Piauí (UFPI). Colégio Técnico de Floriano. Projeto Pedagógico do Colégio Técnico de Floriano. Floriano- PI: UFPI, 2013.

5. Rocha JBB, Nogueira LT, Zeitoune RCG. Among prescribed and the real: (dis)order between the teaching and the practice of the nurse technician. Esc Anna Nery Rev Enferm [Internet]. 2005 [citdo 2020 Mar 2];9(2):237$246 . \quad$ Disponível em: https://pdfs.semanticscholar.org/c68b/15a34b ab1df70477f5c6d5780bf95ab759ce.pdf

6. Basílio AC, Ferro MAB. Nurses from Piaui, who contributed to the brazilian nursing: history and memory of professional experiences. Rev Saud e Desenvol [Internet]. 2012 [citado 2020 Mar 2]; 1(1):68-85. Disponível em: https://www.uninter.com/revistasaude/index.p $\mathrm{hp} /$ saudeDesenvolvimento/article/view/75

7. Santos FBO, Marques RC. Nurses graduated from Escola de Enfermagem Carlos Chagas: Work areas. 1936-1948. Esc Anna Nery [Internet]. 2015 [citado 2020 Mar 2];19(2):363-368. $\quad$ DOI: https://doi.org/10.5935/1414-8145.20150050

8. Silva JL, Machado DM. Brazilian nursing in 90 years of associative history: contributions of the Brazilian Nursing Association. Hist enferm Rev eletronica [Internet]. 2018 [citado 2020 Mar 2];9(2):131-40. Disponível em: http://here.abennacional.org.br/here/v9/n2/a4. pdf

9. Pimenta AL, Souza ML. The professional identity of nursing of nursing in the papers published by Reben. Texto contexto-enferm [Internet]. 2017 [citado 2020 Mar 12]; 26(1):e4370015. DOI: https://doi.org/10.1590/010407072016004370015

10. Lopes RC, Nobrega-Therrien SM, Araújo PAA. The formation of the Nursing Assistant in Ceará - 1954-1961. Hist enferm Rev eletronica [Internet]. 2019 [citado 2020 Mar 12];10(1):10-20. Disponível em: http://here.abennacional.org.br/here/v10/n1/a1 .pdf

11. Meihy JCSB, Ribeiro SLS. Guia prático de história oral: para empresas, universidades, comunidades, famílias. São Paulo: Contexto, 2011. 208p.

12. Brasil. Resolução do Conselho Nacional de Saúde no 466, de 12 de Dezembro de 2012 [Internet]. Brasília: Conselho Nacional de Saúde, 2012 [citado 2020 Mar 12]. Disponível em: https://conselho.saude.gov.br/resolucoes/2012 /Reso466.pdf

13. Instituto Brasileiro de Geografia e Estatística (IBGE). Floriano. 2020 [citado 2020 Sep 20]. Disponível em: https://cidades.ibge.gov.br/brasil/pi/floriano/p anorama

14. Universidade Federal do Piauí (UFPI). Colégio Técnico de Floriano. Projeto Político Pedagógico do Colégio Técnico de Floriano. Floriano- PI: UFPI, 2013.

15. Manzato CRU, Ribeiro ML, Araújo DS. The trajectory of Professional Education of the Nursing Assistant. Rev UNIARA [Internet]. 2012 [citado 2020 Mar 12];15(2):27-39.

DOI: https://doi.org/10.25061/2527-

2675/ReBraM/2012.v15i2.86

16. Sousa ACM, Carvalho CS, Araújo RD. Dossiê UESPI 30 anos: versão comemorativa. Teresina: Fundação Universidade Estadual do Piauí; 2017.

17. Silva KLM, Batista PAB, Nogueira LMSA, Cruz KCT, Faustino AM. Maria Aurineide da Silva Nogueira, protagonist of nursing at the University of Brasília. Hist enferm Rev eletronica [Internet]. 2019 [citado 2020 Set 12];10(1):44-50. Disponível em: http://here.abennacional.org.br/here/v10/n1/a4 .pdf 
18. Gastaldo DM, Meyer DE. A formação da enfermeira: ênfase na conduta em detrimento do conhecimento. Rev Bras Enferm [Internet]. 1989 [citado 2020 Set 12];42(1,2,3/4):7-13. DOI: $\quad$ http://dx.doi.org/10.1590/S003471671989000100002

19. Universidade Federal do Piauí (UFPI). Colégio Técnico de Bom Jesus. 2018 [citado 2020 Sep 12]. Disponível em: ufpi.br/ctbj

20. Machado $\mathrm{MH}$, Wemelinger M, Vieira M, Oliveira E, Lemos W, Aguiar Filho W et al. Aspectos gerais da formação da enfermagem: o perfil da formação dos enfermeiros, técnicos e auxiliares. Enferm Foco [Internet]. 2016 [citado 2020 Set 12];6(2/4):15-34. DOI: https://doi.org/10.21675/2357-

707X.2016.v7.nESP.687

21. Feiber DT, Rodrigues RM, Conterno SFR. História da educação profissionalizante em enfermagem no oeste do paraná: enfoque no centro estadual de educação profissional Pedro Boaretto Neto-CEEP. Educere et educare Rev Educ [Internet]. 2014 [citado 2020 Set 12];9(17):307-15. Disponível em: http://e-

revista.unioeste.br/index.php/educereeteducar e/article/view/8142/7426

22. Caverni LMR. Curso técnico de enfermagem: uma trajetória histórica e legal 1948 a 1973. 2005. Dissertação [Mestrado em Enfermagem]- Escola de Enfermagem, Universidade de São Paulo, São Paulo, 2005 [citado 2020 Set 12]. Disponível em: https://teses.usp.br/teses/disponiveis/7/7131/t de-31012006-111530/pt-

br.php\#: :text=Curso $\% 20 t \% \mathrm{C} 3 \% \mathrm{~A} 9 \mathrm{cnico} \% 2$ 0de\%20enfermagem\%3A\%20uma,e $\% 20$ legal $\% 20 \% 2 \mathrm{D} \% 201948 \% 20 \mathrm{a} \% 201973 \& \mathrm{text}=\mathrm{At} \%$ C3\%A9\%20o\%20presente\%20momento\%2C \%20estudos,s\%C3\%A3o\%20em\%20n\%C3\% BAmero\%20muito\%20reduzido.

\section{Autor correspondente}

Natália Pereira Marinelli

Universidade Federal do Piauí, Campus Petrônio Portela, Colégio Técnico de Teresina, Teresina, Piauí. CEP: 64049-550. Telefone: 86981221975. E-mail: nataliamarinelli@ufpi.edu.br

Submissão: 2021-09-27

Aprovado: 2021-09-13 